\title{
Nursing students' attitudes towards older people and future career choices in Macao-A pilot study
}

\author{
Mei Hua Kerry Hsu*1, Man Ho Ling ${ }^{2}$ \\ ${ }^{1}$ School of Health Sciences, Macao Polytechnic Institute, Macao S.A.R. \\ ${ }^{2}$ The Education University of Hong Kong, Hong Kong S.A.R.
}

Received: December 4, 2017

DOI: $10.5430 /$ jnep.v9n2p10
Accepted: September 5, $2018 \quad$ Online Published: September 25, 2018

URL: https://doi.org/10.5430/jnep.v9n2p10

\begin{abstract}
Background: As global ageing, Macao also faces challenges with regards to an aging population. Not many nursing students are willing to choose gerontological nursing $(\mathrm{GN})$ as a career choice. This pilot study was conducted on a small sample of Macao nursing students to assess nursing students' attitudes towards older people and their future career choices. Moreover, this pilot study is aimed to validate the survey questionnaire for the further study.

Methods: A cross-sectional survey to explore 30 Macao nursing students' attitudes towards older people and future career choices. Kogan's attitudes towards older people scale (KAOP) was adopted in this study.

Results: About 33.3\% nursing students agreed to work in GN after graduation. Only 6.7\% participants chose "aged care institute" as their first choice for future career. Participants have higher mean scores of KAOP that indicate more positive attitudes towards older people. "GN practice experience" and "personal preference" are confirmed as contributors for nursing students towards GN in this study.

Conclusions: Macao nursing students have positive attitudes towards older people but not many of them would choose GN as future career. This pilot study provided knowledge to current nursing educators and government for the situation among nursing students in Macao.
\end{abstract}

Key Words: Nursing student, Attitude towards older people, Career choice

\section{INTRODUCTION}

As global ageing, it is estimated that older population will be nearly double from $12 \%$ to $22 \%$ of the world between 2015 and 2050. ${ }^{[1]}$ Macao also faces challenges with regards to an aging population. In 2016, 9.1\% of Macao's total population of approximately 644,900 people was aged 65 or older and the life expectancies at birth was 83.3 of age, for women and men were 86.4 years and 80.2 years of age respectively. ${ }^{[2]}$ It is estimated that by 2036, 23.7\% of Macao's population will be aged 65 or older. ${ }^{[2,3]}$ As a result, there will be more health care professionals needed to provide direct care to older people in households, communities, and health care settings including clinics, hospitals, and nursing homes. ${ }^{[4,5]}$ Ageing provides challenges and opportunities for the healthcare professionals. The preparation to meet global ageing is important and essential especially for nursing students, as they will provide direct care to older population after graduation. As nursing students will play a critical role in caring for the increasing elderly population, it is important that they possess the necessary skills to care for the elderly and also maintain positive attitudes towards elderly people.

Studies concluded most new nursing graduates would be commonly and often working with older people ${ }^{[6]}$ such as A.R. 
nursing home and elderly adult day care centers, even though they do not want to choose gerontological nursing as their first job after graduation. ${ }^{[6-9]}$ Unfortunately, many countries are finding it difficult to recruit enough nurses to provide gerontological care ${ }^{[4,10,11]}$ or to provide direct care to older people. Some nursing students showed they have positive attitudes towards older people, but they did not want to work at gerontological setting after graduation. ${ }^{[12,13]}$ A study addressed relatively few nursing students are willing to choose gerontology as a career choice and nursing students having negative attitudes ${ }^{[14]}$ towards older people that would lead the consequence for not working in GN settings after graduation.

Nursing education has been reported to play a significant role in changing nursing students' attitudes towards older people and promoting their willingness to work in gerontological setting after graduation. ${ }^{[13]}$ A unique course in gerontological nursing (GN) including theory course and clinical practice delivered for Bachelor of Science in Nursing (BSN) programme have been linked to promote nursing students' attitudes and interests for working in GN settings after graduation. ${ }^{[4,15,16]}$ Given the situation of global ageing GN course has been adopted and delivered as a compulsory unique subject in Macao since 2008 including theory class and clinical practice. Macao nursing students' attitudes towards older people and working in GN after graduation have been not yet explored. The more understanding in nursing students' attitudes towards older people and future career choices, the better preparation in GN course encouraging more nursing students working in GN after graduation.

This study was conducted on a small sample of Macao nursing students to assess nursing students' attitudes towards older people and their future career choices. Moreover, this pilot study was aimed to validate the survey questionnaire for the further main study.

\section{MethodS}

\subsection{Design}

This pilot study used a descriptive, non-experimental, crosssectional survey to assess Macao nursing students' attitudes towards older people and future career choices. The convenience sampling method was used to collect data for this pilot study. All participants were invited and voluntary to join this pilot study. A test-retest design was utilized to examine the reliability of KAOP in Macao.

\subsection{Participants and setting}

The 4-year BSN programme in Macao provides a compulsory and stand-alone GN course including theory classes and clinical practice at Year III. This pilot study was conducted at one of higher nursing education institutes and including 30 un- dergraduate nursing students as this institute produces 50-60 graduates to be registered nurses in Macao every year. This study was conducted on a small sample of Macao nursing students to have the basic understandings for their attitude towards old people and future career choices, furthermore to validate the survey questionnaire for the future study in Macao.

There were inclusion criteria for participants in this study: 1) A nursing student in the BSN program, 2) vulnerary to join this study and 3) willingness to participant this study for the test-retest survey. Exclusion criteria were 1) no interest in this study, and 2) lack of time to participant test-retest survey in the study.

\subsection{Instrument}

The questionnaire was designed as a self-administered questionnaire containing seven components: demographic, experience with older people, intention with older people, GN education, future career choices, and Kogan's attitude towards old people scale (KAOP). The questionnaire will take approximately 30 to 60 minutes for the completion.

The Chinese Version of Kogan's Attitude towards Older People is adopted to explore nursing students' attitude towards aging in Macao. KAOP (1961) was developed to assess attitude towards elderly people ${ }^{[17]}$ with respect to norms and individual differences, stereotypes of old people, and misconceptions about older people. ${ }^{[18]} \mathrm{KAOP}$ is still the most commonly used questionnaire in attitudes towards older people, as its various translations have good content validity, construct validity, internal consistency and stability reliability which have been reported for both variants of the instrument. ${ }^{[19]}$ Reliability and concurrent validity have been addressed by Kogan (1961), who reported item-total scale correlations among undergraduate American subjects in the range of $0.10-0.70$. For the Japanese version the Cronbach's alpha was 0.87 for the total scale, ${ }^{[20]}$ for the Greek version $0.80^{[21,22]}$ for the Turkish version $0.84^{[19]}$ and for the Swedish version $0.79 .{ }^{[23]}$

The average of the content validity index (CVI) in Chinese version of KAOP was 0.92 in the final version indicating adequate content validity $>.80 .{ }^{[24,25]}$ The Crobach's alpha was 0.82 for the total ( 0.83 for Prejudice, 0.81 for Appreciation), stability was 0.86 for Prejudice and 0.91 for Appreciation, and adequate for Chinese version of Kogan's Attitude towards older people. ${ }^{[25]}$ The higher score of KAOP indicated more positive attitude toward older people.

\section{Validity of instrument}

This research adopted CVI as the indicator of validity. Content validity is indicated if the items in the tool sample the 
complete range of the attribute under study. Five experts who have over ten-year experiences in clinical practice, long-term care center, education of gerontological nursing in Macao were invited to review the questionnaire items and validate that they are relevant indicators of the construct. Item-level Content Validity Index (I-CVI) and Scale-Level Content Validity Index (S-CVI) were calculated by the rating scores from experts. This study followed criteria a minimum ICVI of 0.78 and it would have an average S-CVI of 0.90 or higher. ${ }^{[24]}$ The results of validity are I-CVI .988 and S-CVI .933 which represents this questionnaire has good and stable validity. According to the comments and suggestions from experts, the questionnaire has been modified words and items for better understanding to participants in this pilot study.

\subsection{Data collection procedure}

Data were collected via validated questionnaire to participants. Participants were recruited through invitation. Thirty nursing students were volunteers to join this study. This pilot study conducted in Jan 2015 and there was no major examination during data collection period. The investigator met participants and explained the purpose and procedure of this study to participants. Participants were guaranteed that their personal data will be replaced by codes, and all data would be kept as confidential. All participants signed and returned written consents. Thirty self-administrated survey questionnaires were distributed to participants. All questionnaires were finished and returned by participants within one hour. Two weeks following the first completion of pilot test, another KAOP form was given to 30 student nurses for the follow up.

\subsection{Data analysis}

This study used Statistical Package for the Social Sciences (SPSS) 20.0 for data analysis.

Descriptive statistics, including measurements of frequency distributions (percent of participant) and central tendency (mean) as well as measures of dispersion or variability (standard deviation), were utilized to organize and summarize findings, including demographic data to provide information about the characteristics of the participants, experience with older people, intention with older people, GN education, and future career choice.

The KAOP tool consisted of 34 items regarding older people; one set of 17 items expressing negative statements (KAOP-), and another set of 17 items expressing positive statements (KAOP+). It is designed as a summed Likert attitude scale on a six-point response categories that ranges from 1 (strongly disagree) to 7 (strongly agree). These categories were scored $1,2,3,5,6$, and 7 , respectively, with a score of 4 assigned in the rare case of failure to respond to an item. ${ }^{[17]}$ The KAOP instrument is uniquely constructed to yield three distinct measures; KAOP total score, and two subscales, the $\mathrm{KAOP}+$ subscale and the KAOP- subscale. In the computation of scores, negatively worded items are reversed scored to obtain the KAOP total score. The possible score ranges from $34-238$, and a higher score indicates a more positive attitude. For the Chinese version, the internal consistency reliability (Cronbach's alpha) was 0.82 for the total scale (0.83 for KAOP-, 0.81 for KAOP+). ${ }^{[25]}$ In this pilot study, internal consistency reliability and stability of KAOP were assessed. Cronbach's alpha was used to estimate the internal consistency reliability. Stability was assessed using a repeated measure design with a 2-week interval by Pearson correlations.

\subsection{Ethical considerations}

Ethical approvals for data collection were obtained and granted from The Education University of Hong Kong and Macao Polytechnic Institute ethics committees prior to commencing this pilot study. All participants have been provided the information sheets about the purpose, the procedure, and the opportunity to withdraw of the study. All participants provided informed consents after the brief introduction by principal investigator. Confidentiality and anonymous were assured. All personal data were replaced by codes and number in the study.

\section{RESUltS}

\subsection{Descriptive data}

Thirty nursing students completed survey questionnaires within one hour. Demographic data of nursing students are summarized in Table 1. Most participants were female nursing students (80\%) in this study with mean age 21.6 (SD = 1.75). $80 \%(\mathrm{n}=24)$ nursing students in this study answered no religion. Nursing students' experiences with older people are addressed in Table 2. Most nursing students reported "getting along with 65+" with "good" or "very good" (80\%) although only $46.7 \%$ nursing students reported they "lived with $65+$ ". $30 \%(\mathrm{n}=9)$ participants were "raised up by $65+$ ". As year III nursing students were doing clinical practice, so this pilot study did not have participant from year III nursing students.

In intention with older people (see Table 3), most nursing students (63.4\%) reported "agree" or "strongly agree" to "live with 65+" in the future. Most nursing students expressed (see Table 4) "nursing is the first choice for studying in university" (86\%). GN taught subject and clinical practicum were evaluated by nursing students as "fair" $(53.3 \%$ and $43.3 \%$ respectively). 
Table 1. Demographic data of participants $(n=30)$

\begin{tabular}{llllll}
\hline Variables & & $\mathbf{n}$ & $\mathbf{\%}$ & Mean & Standard Deviation \\
\hline Age & & 30 & & 21.6 & 1.75 \\
Gender & Male & 6 & 20 & \\
& Female & 24 & 80 & \\
Education & BSN Year I & 8 & 26.7 & \\
& BSN Year II & 8 & 0 & \\
& BSN Year III & 0 & 46.7 & \\
& BSN Year IV & 14 & 80 & \\
Religion & None & 24 & 3.3 & \\
& Buddhist & 1 & 3.3 & \\
& Taoism & 1 & 10 & \\
& Catholic & 3 & 3.3 & \\
\hline
\end{tabular}

Table 2. Experience with ageing $(\mathrm{n}=30)$

\begin{tabular}{|c|c|c|c|}
\hline Variable & & $\mathbf{n}$ & $\%$ \\
\hline \multirow{2}{*}{ Family status } & Living with parents and sibling & 29 & 96.3 \\
\hline & Living with grand-parents, parents and sibling & 1 & 3.3 \\
\hline \multirow{2}{*}{ Living with $65^{+}$} & No & 28 & 93.3 \\
\hline & Yes & 2 & 6.7 \\
\hline \multirow{2}{*}{ Neighbor with 65+ } & No & 19 & 63.3 \\
\hline & Yes & 11 & 36.7 \\
\hline \multirow{2}{*}{ Raised up by 65+ } & No & 21 & 70 \\
\hline & Yes & 9 & 30 \\
\hline \multirow{2}{*}{ Lived with $65+$} & No & 16 & 53.3 \\
\hline & Yes & 14 & 46.7 \\
\hline \multirow{3}{*}{ Getting along with $65+$} & Fair & 6 & 20 \\
\hline & Good & 17 & 56.7 \\
\hline & Very good & 7 & 23.3 \\
\hline
\end{tabular}

Table 3. Intention factor $(n=30)$

\begin{tabular}{|c|c|c|c|}
\hline Variable & & $\bar{n}$ & $\%$ \\
\hline \multirow{4}{*}{ Like to spend time with $65^{+}$} & Disagree & 1 & 3.3 \\
\hline & Don't mind & 8 & 26.7 \\
\hline & Agree & 18 & 60 \\
\hline & Strongly Agree & 2 & 6.7 \\
\hline \multirow{4}{*}{ To live with $65+$ in the future } & Disagree & 1 & 3.3 \\
\hline & Don't mind & 10 & 33.3 \\
\hline & Agree & 17 & 56.7 \\
\hline & Strongly Agree & 2 & 6.7 \\
\hline \multirow{3}{*}{ Filial Piety for every one } & Don't mind & 1 & 3.3 \\
\hline & Agree & 12 & 40 \\
\hline & Strongly Agree & 17 & 56.7 \\
\hline
\end{tabular}

\subsection{Future career choice and affecting factors}

About $33.3 \%$ nursing students agreed to work in GN after graduation. Nursing students rated the first important factor to affect choice in working in GN were GN practice experience $(33.3 \%)$ and personal preference $(33.3 \%)$ (see Table 5 and Figure 1). Participants' first preference for future nursing work was midwifery (30\%), only $6.7 \%$ participants chose "aged care institute" as their first choice for future career (see Table 6 and Figure 2). 
Table 4. GN Study and GN clinical experience $(\mathrm{n}=30)$

\begin{tabular}{|c|c|c|c|}
\hline Variable & & $\mathbf{n}$ & $\%$ \\
\hline \multirow{2}{*}{ Clinical practice experience with $65+$} & None & 4 & 13.3 \\
\hline & Yes & 26 & 86.7 \\
\hline \multirow{2}{*}{ Clinical practice experience with $65+$} & Fair & 6 & 20 \\
\hline & Good & 24 & 80 \\
\hline \multirow{2}{*}{ Nursing is my first study choice } & No & 4 & 13.3 \\
\hline & Yes & 26 & 86.7 \\
\hline \multirow{3}{*}{ Working in GN after graduation } & Disagree & 3 & 10 \\
\hline & Don’t mind & 17 & 56.7 \\
\hline & Agree & 10 & 33.3 \\
\hline \multirow{2}{*}{ Family working in Nursing } & No & 27 & 90 \\
\hline & Yes, not related to GN & 3 & 10 \\
\hline \multirow{3}{*}{ Experience of GN taught subject } & Not Applicable & 10 & 33.3 \\
\hline & Fair & 16 & 53.3 \\
\hline & Good & 4 & 13.3 \\
\hline \multirow{4}{*}{ Experience of GN clinical practice } & Not Applicable & 10 & 33.3 \\
\hline & Poor & 1 & 3.3 \\
\hline & Fair & 13 & 43.3 \\
\hline & Good & 6 & 20 \\
\hline
\end{tabular}

\subsection{Attitude towards old people scale (KAOP)}

The internal consistency and stability were adopted to evaluate the reliability of KAOP. Cronbach's alpha was used to estimate the internal consistency reliability. Stability was assessed using a repeated measure design with a 2-week interval by Pearson correlations. The results of KAOP are shown in Table 6. Participants have higher mean scores of KAOP for the first time (Mean $=167.83, \mathrm{SD}=15.86)$ and the second time $($ Mean $=166.43, \mathrm{SD}=16.97)$. The higher mean scores indicated more positive attitudes towards older people among participants.

\subsubsection{Stability reliability- test-retest reliability of KAOP}

In order to determine the stability reliability of Kogan's attitude towards old people scale. The retest of KAOP was applied after two weeks to 30 nursing students. The correlation between the first time test and retest (two weeks later) was calculated with Pearson-Correlation Analysis (see Table 6). The correlation for the total score was $r=0.73$ at a significance of $p<.01$. Stability reliability was adequate in this pilot study.

\subsubsection{Reliability- internal consistency of KAOP}

The internal consistency of KAOP was measured by the Cronbach alpha test (see Table 7). Cronbach alpha for the first time and 2nd time (two weeks later) were 0.84 and 0.86 respectively for the total items of KAOP that indicate good internal consistency reliability as coefficients of .80 or greater are highly desirable. ${ }^{[24]}$

\section{Discussion}

This pilot research provided the basic understanding in Macao nursing students' experiences with older people, in14 tentions with older people, experiences GN education, future career choices and contributors, and attitude towards older people among nursing students in Macao.

\subsection{Future career choices}

In this pilot study, Macao nursing students reported getting along with $65+(80 \%)$ and like to spend time with $65+$ $(66.7 \%)$ in the future but only $33.3 \%(\mathrm{~N}=10)$ nursing students will want to work in GN after graduation. The findings showed 33.3\% Macao nursing students in this study agreed to work in GN after graduation, though previous studies concluded nursing students did not want to work at gerontological nursing settings. ${ }^{[26-30]}$ The finding is lower than previous two studies that concluded higher percentages of nursing students from China (72.1\%), Australia (45.3\%) and Sweden (58\%) would like to work with older people after graduation. ${ }^{[31,32]}$ On the other hand, only $6.7 \%$ Macao nursing students in this study chose "aged care institute" as their first choice for future career. This finding has almost the same result which compared existing researches for working in gerontological nursing- in Belgium, $8.6 \%$ of qualified nurses; ${ }^{[15]}$ in Australia, $8 \%$ of nursing students for possible career choices; ${ }^{[30]}$ in Jordan, $62 \%$ of qualified nurses said they were positively uninterested in gerontological care. ${ }^{[33]}$ This study showed almost the same result with previous studies elsewhere. For the current situation, most nurses in Macao would like to work at the only public hospital or public care centers as more benefits and better future. Aged care centers or long-term care centers may not have the good benefits than public settings, thus not many nursing students in this study chose aged care center as their future career choices.

ISSN 1925-4040 E-ISSN 1925-4059 
Table 5. Future career choices $(n=30)$

1. The first important factor to affect choice in working in
GN

2. The second important factor to affect choice in working in GN

3. The Third important factor to affect choice in working in GN

4. The first preference future nursing work

5. The second preference future nursing work

6. The third preference future nursing work

GN practice experience
Personal preference
Past experience with $65^{+}$
Working environment
Salary
Society factor and social value
Working environment

Salary

Past experience with 65+

Role model-affected by tracher or preceptors

Personal preference

GN Practice experience

Society factor and social value

Peer group-affected by classmates

Society factor and social value

Past experience with 65+

Working environment

Salary

GN practice experience

Suggestion by parents and family

Personal preference

Peer group-affected by classmates

Midwifery

Publichealth nursing

Medical/surgical nursing

Psychiatric nursing

Aged care institute

Critical care nursing

Paediatric nursing

Other-ER

nurse anesthetist

Critical care nursing

Publichealth nursing

Paediatric nursing

Psychiatric nursing

Medical/surgical nursing

Home care nursing

Operating room nursing

Aged care institute

Midwifery

Oncology nursing

Psychiatric nursing

Critical care nursing

Midwifery

Aged care institute

nurse anesthetist

Paediatric nursing

Medical/surgical nursing

Operating room nursing

Publichealth nursing

Home care nursing

Oncology nursing

\begin{tabular}{|c|c|}
\hline $\mathbf{n}$ & $\%$ \\
\hline 10 & 33.3 \\
\hline 10 & 33.3 \\
\hline 5 & 16.7 \\
\hline 3 & 10 \\
\hline 1 & 3.3 \\
\hline 1 & 3.3 \\
\hline 6 & 20 \\
\hline 6 & 20 \\
\hline 4 & 13.3 \\
\hline 4 & 13.3 \\
\hline 4 & 13.3 \\
\hline 3 & 10 \\
\hline 2 & 6.7 \\
\hline 1 & 3.3 \\
\hline 7 & 23.3 \\
\hline 5 & 16.7 \\
\hline 5 & 16.7 \\
\hline 4 & 13.3 \\
\hline 3 & 10 \\
\hline 3 & 10 \\
\hline 2 & 6.7 \\
\hline 1 & 3.3 \\
\hline 9 & 30 \\
\hline 6 & 20 \\
\hline 3 & 10 \\
\hline 3 & 10 \\
\hline 2 & 6.7 \\
\hline 2 & 6.7 \\
\hline 2 & 6.7 \\
\hline 2 & 6.7 \\
\hline 1 & 3.3 \\
\hline 7 & 23.3 \\
\hline 5 & 16.7 \\
\hline 4 & 13.3 \\
\hline 4 & 13.3 \\
\hline 3 & 10 \\
\hline 2 & 6.7 \\
\hline 2 & 6.7 \\
\hline 1 & 3.3 \\
\hline 1 & 3.3 \\
\hline 1 & 3.3 \\
\hline 5 & 16.7 \\
\hline 4 & 13.3 \\
\hline 4 & 13.3 \\
\hline 3 & 10 \\
\hline 3 & 10 \\
\hline 3 & 10 \\
\hline 2 & 6.7 \\
\hline 2 & 6.7 \\
\hline 2 & 6.7 \\
\hline 1 & 3.3 \\
\hline 1 & 3.3 \\
\hline
\end{tabular}




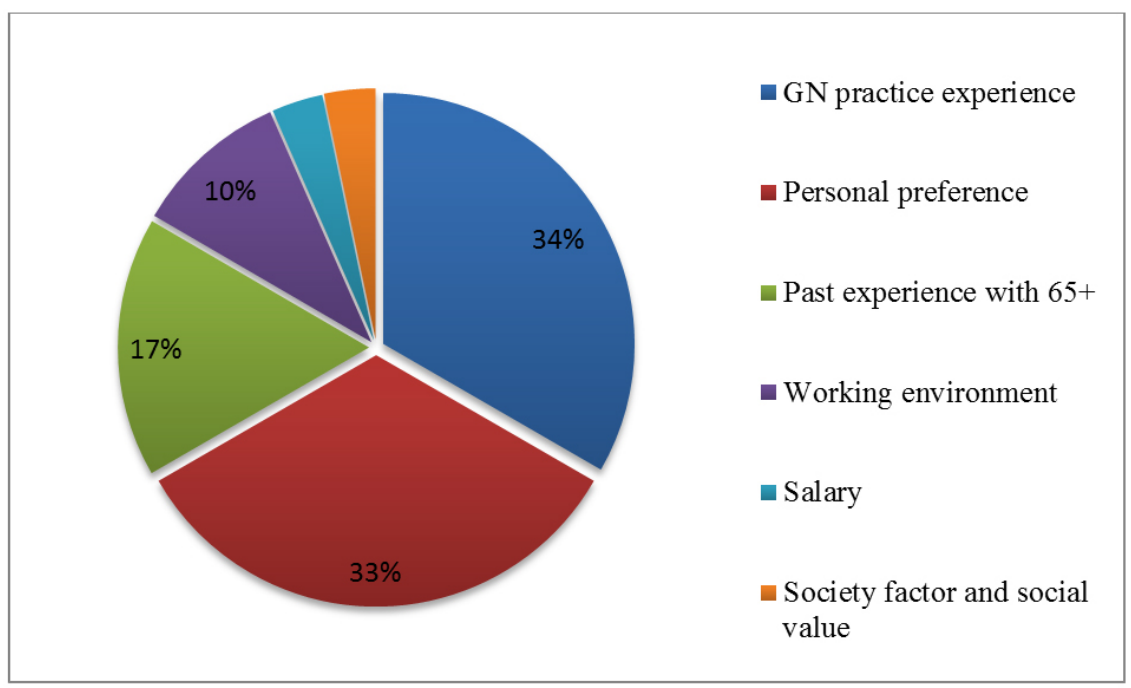

Figure 1. The first important factor to affect choice in working in GN

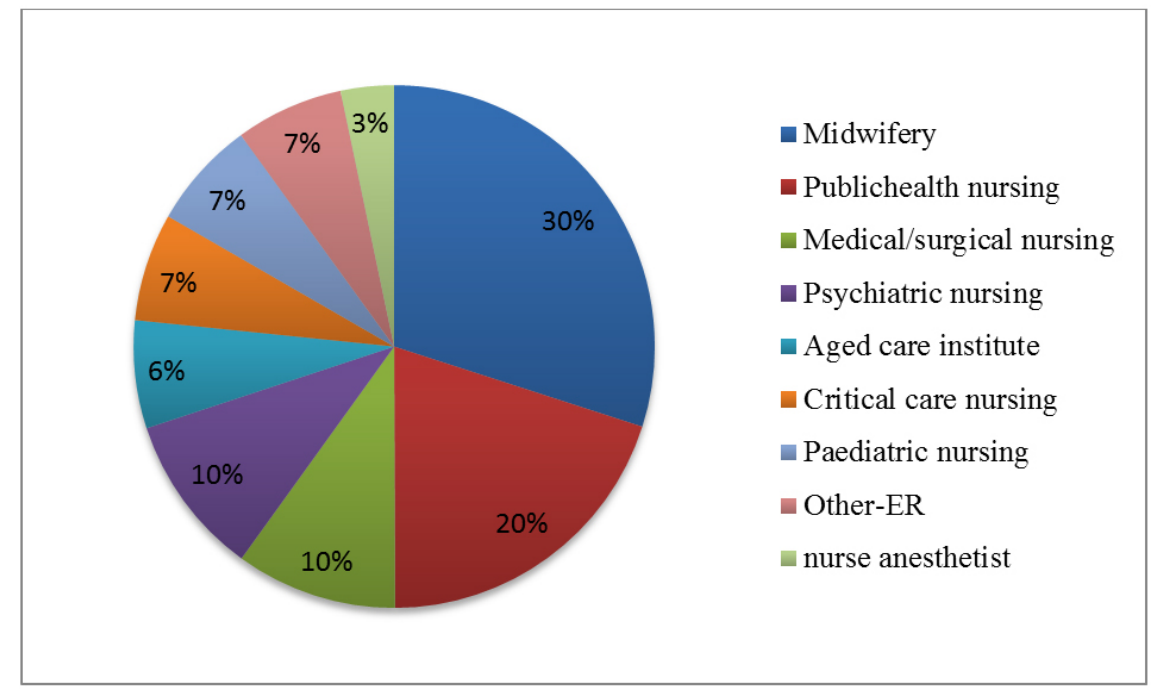

Figure 2. The first preference future nursing work

Nursing students in Macao reported their first preference future nursing work should be midwifery (30\%), second preference working place was critical care nursing $(23.3 \%)$, and the third preference was psychiatric nursing $(16.7 \%)$ which showed different from the finding about nursing students tend to work in "high-tech" settings such as surgical nursing, intensive care and operating. ${ }^{[30]}$ The results could be related to the stable birth rates in Macao, though critical care nursing was also rated the secon preference future work in Macao.

Macao nursing students addressed "GN practice experience" and "personal preference" would be important as the first important factor to affect their choices in working GN. These two findings match with previous findings ${ }^{[34,35]}$ that the effect of clinical experiences was the most profound factor influencing career choice after graduation. GN practice expe- rience and personal preference are important factors among nursing students in this study for working in the GN, the results provided evidence to nursing educators in the better arrangement of GN practice setting, as well as in promoting nursing students' interests to GN. This pilot study was conducted in small sample of 30 nursing students; the results will provide evidences for the further study.

\subsection{Attitudes towards older people}

KAOP was applied to explore Macao nursing students' attitudes towards older people. The result of KAOP scores indicated high internal consistency reliability and adequate stability reliability, as well as good content validity. The mean scores of KAOP among 30 Macao nursing students were $167.83(\mathrm{SD}=15.86)$ for the first time and 166.43 (SD 
$=16.97)$ for the second time that represented more positive participants. Participants showed more positive attitudes in score than recently studies in Korean, ${ }^{[36]}$ Taiwan, ${ }^{[37]}$ and "the elderly are different from one another", but they did not China. ${ }^{[38]}$ In item "6N. Wisdom does not come with ad- think "wisdom comes with advance age". This results provancing age" was the lowest score while "13P. The elderly vide directions to nursing educators for the couse preparation are different from one another." had the higher score among of GN programme in the future.

Table 6. Attitude towards old people scale $(\mathrm{n}=30)$

\begin{tabular}{|c|c|c|c|c|c|c|c|c|c|}
\hline \multirow[b]{2}{*}{ Variable } & \multicolumn{4}{|c|}{ First time } & \multicolumn{3}{|c|}{ 2nd time ( 2 weeks later) } & \multirow[b]{2}{*}{$r$} & \multirow[b]{2}{*}{$p$} \\
\hline & $\mathbf{n}$ & $\begin{array}{l}\text { Min- } \\
\text { Max }\end{array}$ & Mean & SD & $\begin{array}{l}\text { Min- } \\
\text { Max }\end{array}$ & Mean & SD & & \\
\hline Total score & 30 & $\begin{array}{l}122- \\
206\end{array}$ & 167.83 & 15.86 & $\begin{array}{l}127- \\
207\end{array}$ & 166.43 & 16.97 & $0.729 * *$ & .00 \\
\hline $1 \mathrm{~N}$. The elderly should live in special residences. & 30 & $2-7$ & 4.9 & 1.42 & $2-7$ & 4.9 & 1.54 & $0.783^{* *}$ & .00 \\
\hline 2N. The elderly are different. & 30 & $2-7$ & 4.17 & 1.56 & $2-6$ & 4.37 & 1.43 & $0.469 * *$ & .00 \\
\hline 3N. The elderly are unable to change. & 30 & 3-7 & 5.17 & 1.12 & $3-6$ & 5.23 & 0.90 & $0.717^{* *}$ & .00 \\
\hline 4N. The elderly quit work when they become pensioners. & 30 & $1-7$ & 5.1 & 1.21 & $3-7$ & 5.43 & 0.73 & $0.379 *$ & .039 \\
\hline $5 \mathrm{~N}$. The elderly have shabby homes. & 30 & 3-7 & 5.87 & 1.22 & $2-7$ & 5.63 & 1.22 & $0.614^{* *}$ & .00 \\
\hline 6N. Wisdom does not come with advancing age. & 30 & $2-6$ & 3.43 & 1.35 & $2-6$ & 3.20 & 1.10 & $0.404^{*}$ & .027 \\
\hline $7 \mathrm{~N}$. The elderly have too much influence in society. & 30 & $2-6$ & 3.87 & 1.36 & $2-6$ & 3.90 & 1.32 & $0.549 * *$ & .002 \\
\hline $8 \mathrm{~N}$. The elderly make others feel ill at ease. & 30 & $3-6$ & 5.37 & 0.85 & $3-7$ & 5.50 & 1.04 & $0.525^{* *}$ & .003 \\
\hline 9N. The elderly bore others with their stories. & 30 & $2-7$ & 4.97 & 1.59 & $2-7$ & 4.97 & 1.47 & $0.840^{* *}$ & .00 \\
\hline $10 \mathrm{~N}$. The elderly are always prying into the affairs of others. & 30 & 3-7 & 5.47 & 1.33 & $2-7$ & 5.20 & 1.24 & $0.775^{* *}$ & .00 \\
\hline $11 \mathrm{~N}$. The elderly have irritating faults. & 30 & $3-7$ & 5.43 & 1.01 & $2-7$ & 5.23 & 1.14 & $0.422^{*}$ & .02 \\
\hline 12N. The elderly have a negative influence on a neighborhood. & 30 & $2-7$ & 5.57 & 0.97 & $2-7$ & 5.40 & 1.16 & $0.769 * *$ & .00 \\
\hline 13N. The elderly are much alike. & 30 & $2-7$ & 4.47 & 1.46 & $2-7$ & 4.53 & 1.36 & $0.724 * *$ & .00 \\
\hline $14 \mathrm{~N}$. The elderly are untidy. & 30 & $3-7$ & 5.80 & 0.85 & $3-7$ & 5.77 & 0.86 & $0.787^{* *}$ & .00 \\
\hline $15 \mathrm{~N}$. The elderly are irritable, grouchy and unpleasant. & 30 & 3-7 & 5.60 & 0.93 & 3-7 & 5.53 & 1.07 & $0.771^{* *}$ & .00 \\
\hline $16 \mathrm{~N}$. The elderly complain about the young. & 30 & $3-7$ & 5.50 & 1.08 & 3-7 & 5.23 & 1.28 & $0.590^{* *}$ & .001 \\
\hline $17 \mathrm{~N}$. The elderly have excessive demands for love. & 30 & $1-5$ & 2.37 & 0.93 & $1-6$ & 2.57 & 1.22 & 0.358 & .05 \\
\hline 1P. The elderly should live integrated with the young. & 30 & $3-6$ & 4.77 & 1.07 & $2-6$ & 4.47 & 1.11 & $0.60 * *$ & .001 \\
\hline 2P. The elderly are no different from anyone else. & 30 & $2-7$ & 2.37 & 0.93 & $2-7$ & 4.63 & 1.50 & $0.57 * *$ & .001 \\
\hline 3P. The elderly are capable of new adjustment. & 30 & $3-7$ & 5.30 & 0.84 & $2-7$ & 4.93 & 1.29 & $0.597 * *$ & .001 \\
\hline 4P. The elderly prefer to work as long as they can. & 30 & $3-7$ & 5.43 & 0.86 & $3-7$ & 5.17 & 1.02 & $0.427 *$ & .019 \\
\hline 5P. The elderly have clean, attractive homes. & 30 & $2-6$ & 4.97 & 1.10 & $2-6$ & 4.77 & 1.33 & $0.561 * *$ & .001 \\
\hline 6P. The elderly grow wiser with advancing age. & 30 & $1-6$ & 3.73 & 1.36 & $1-6$ & 3.93 & 1.39 & $0.428 *$ & .018 \\
\hline 7P. The elderly should have more power in society. & 30 & $2-6$ & 4.47 & 1.11 & $1-6$ & 4.47 & 1.38 & $0.552^{* *}$ & .002 \\
\hline 8P. The elderly are relaxing to be with. & 30 & $2-6$ & 4.80 & 1.19 & 3-7 & 4.97 & 1.13 & $0.716^{* *}$ & .00 \\
\hline 9P. It is nice when the elderly speak about their past. & 30 & $2-7$ & 5.53 & 1.07 & $3-7$ & 5.60 & 1.04 & $0.508^{* *}$ & .004 \\
\hline 10P. The elderly mind their own business. & 30 & 3-6 & 4.87 & 1.14 & $2-6$ & 5.03 & 1.03 & $0.503^{* *}$ & .005 \\
\hline 11P. The elderly have the same faults as the young. & 30 & $3-7$ & 5.20 & 1.03 & $3-7$ & 5.40 & 0.97 & $0.712^{* *}$ & .00 \\
\hline 12P. Neighborhoods are nice when integrated with the elderly. & 30 & $3-7$ & 5.77 & 0.82 & $3-7$ & 5.47 & 1.04 & $0.375^{*}$ & .041 \\
\hline 13P. The elderly are different from one another. & 30 & $5-7$ & 6.00 & 0.70 & $3-7$ & 5.80 & 0.89 & $0.392 *$ & .032 \\
\hline 14P. The elderly are clean and neat. & 30 & 3-7 & 4.60 & 1.25 & $2-6$ & 4.67 & 1.27 & 0.305 & .101 \\
\hline 15P. The elderly are cheerful, agreeable and good-humored. & 30 & $2-6$ & 4.83 & 1.02 & 3-6 & 4.77 & 1.07 & $0.531^{* *}$ & .003 \\
\hline 16P. The elderly seldom complain about the young. & 30 & $2-6$ & 4.03 & 1.25 & $2-6$ & 4.00 & 1.29 & $0.474^{* *}$ & .008 \\
\hline 17P. The elderly need no more love than others. & 30 & 3-7 & 5.83 & 1.12 & $3-7$ & 5.77 & 1.28 & 0.31 & .095 \\
\hline
\end{tabular}


Table 7. The internal reliability of KAOP $(n=30)$

\begin{tabular}{lll}
\hline Item & $\begin{array}{l}\text { Cronbach alpha } \\
\text { (First time) }\end{array}$ & $\begin{array}{l}\text { Cronbach alpha } \\
\text { (Two weeks later) }\end{array}$ \\
\hline Total items of KAOP & 0.84 & 0.86 \\
KAOP- & 0.69 & 0.68 \\
KAOP+ & 0.85 & 0.87 \\
\hline
\end{tabular}

Macao nursing students showed more positive attitudes towards older people in this pilot study. As this pilot study only included 30 Macao nursing students, it is needed to explore Macao all nursing students' attitudes towards older people. This result also provided information to compare with related studies among nursing students elsewhere, as well as to provide the basic understanding for the future study.

\subsection{Limitations of this study}

There were some limitations in this study. This study was conducted at one institution in Macao, and 30 participants may not be representatives of nursing students in general. This pilot study did not involve Year III nursing students as they were out of campus for clinical practice. Moreover, nursing students were voluntary to join this survey who may have positive attitudes towards older people and lead to the positive results in this study. Finally, this pilot study did not adopt qualitative part to explore nursing students' views and thoughts towards GN or working with older people.

\subsection{Suggestion for future study}

It is suggested that the future study might explore all nursing students in Macao for their attitudes towards older people and career choices. The future study might consider using longitudinal design to follow up nursing students' changes from year 1 to 4 during their BSN study. Moreover, nursing students' views and perception for GN education need to be explored in the future.

\section{Conclusion}

The pilot study provided information as evidences for the further study including the method for data collection, analysis, and validity and reliability of instrument. The finding from this pilot study indicated Macao nursing students have positive attitudes towards older people but not many of them would choose GN as future career. The results provided knowledge to educators for the better preparation of GN programme.

The contributors towards working in GN after graduation among Macao nursing students include GN practice experiences and personal preferences. As a result, there would be a need to further explore all nursing students' attitudes towards older people and their future career choices in Macao. This study concluded the survey questionnaire has the adequate validity and reliability; it will be suitable to survey all nursing students' career choices and attitudes towards older people in Macao. Moreover, findings from this pilot study also provided knowledge to current nursing educators and government for the situation among nursing students in Macao.

\section{ACKNOWLEDGEMENTS}

This research was funded by Macao Polytechnic Institute (No.RP/ESS-01/2014).

\section{CONFLicts OF InTEREST Disclosure}

The authors declare that there is no conflict of interest.

\section{REFERENCES}

[1] World Health Organization. WHO: Number of people over 60 years set to double by 2050; major societal changes required 2015 . Available from: http://www.who.int/mediacentre/news/rel eases/2015/older-persons-day/en/

[2] Macao Statistics and Census Service. Life expectancy at birth 2016. [cited 2017]. Available from: http: //www.dsec.gov.mo/Statistic . aspx?NodeGuid=7bb8 $808 e-8 f d 3-4 d 6 b-904 a-34 f e 4 b 302883$

[3] Macao Statistics and Census Service. Health Statistics 2016. [cited 2017]. Available from: http://www.dsec.gov.mo/TimeSeries Database.aspx

[4] Koh LC. Student attitudes and educational support in caring for older people-A review of literature. Nurse Education in Practice. 2012 12(1): 16-20. PMid:21601527 https://doi.org/10.1016/j.ne pr.2011.04.007

[5] Lun M. Student knowledge and attitudes toward older people and their impact on pursuing aging careers. Educational Gerontology.

\section{1; 37(1): 1-11.}

[6] Bleijenberg N, Jansen MJM, Schuurmans MJ. Dutch nursing students' knowledge and attitudes towards older people-A longitudinal cohort study. Journal of Nursing Education \& Practice. 2012; 2(2): 1-7. https://doi.org/10.5430/jnep.v2n2p1

[7] Robinson A, Cubit K. Caring for older people with dementia in residential care: Nursing students' experiences. Journal of Advanced Nursing. 2007; 59(3): 255-63. PMid:17537198 https: //doi.org/10.1111/j.1365-2648.2007.4304.x

[8] Williams KN, Nowak J, Scobee RL. Fostering student interest in geriatric nursing: Impact of senior long-term care experiences. Nursing Education Perspectives. 2006; 27(4): 190-3. PMid:16921803

[9] Wray N, McCall L. Plotting careers in aged care: Perspectives of medical, nursing, allied health students and new graduates. Educational Gerontology. 2007; 11: 939-54.

[10] Goncalves DC. From loving grandma to working with older adults: promoting positive attitudes towards aging. Educational Gerontology. 
2009; 35(3): 202-25. https://doi.org/10.1080/0360127080 2466884

[11] Shen J, Xiao LD. Factors affecting nursing students' intention to work with older people in China. Nurse Education Today. 2012; 32(3): 21923. PMid:21543142 https ://doi . org/10.1016/j .nedt. 2011. 03.016

[12] Henderson J, Xiao L, Siegloff L, et al. Older people have lived their lives: First year nursing students' attitudes towards older people. Contemporary Nurse. 2008; 30(1): 32-45. https ://doi .org/10 $.5172 /$ conu. 673.30 .1 .32

[13] King BJ, Roberts TJ, Bowers BJ. Nursing student attitudes toward and preferences for working with older adults. Gerontology \& Geriatrics Education. 2013; 34(3): 272-91. PMid:23383875 https://doi.org/10.1080/02701960.2012.718012

[14] Abreu M, Caldevilla N. Attitudes toward aging in Portuguese nursing students. Procedia - Social and Behavioral Sciences. 2015; 171(0): 961-7.

[15] Deschodt M, Milisen K. Gerontological care in nursing education programmes. Journal of Advanced Nursing. 2010; 66(1): 139-48. PMid:19968723 https://doi .org/10.1111/j.1365-2648. 20 $09.05160 . x$

[16] Gonçalves DC, Guedes J, Fonseca AM, et al. Attitudes, knowledge, and interest: Preparing university students to work in an aging world. International Psychogeriatrics. 2011; 23(2): 315-21. PMid:20843393 https://doi.org/10.1017/S1041610210001638

[17] Kogan N. Attitudes toward old people: The development of a scale and an examination of correlations. Journal of Abnormal and Social Psychology. 1961; 62(1): 44-54. https://doi.org/10.1037/h0 048053

[18] Lee YS. Measures of student attitudes on aging. Educational Gerontology. 2009; 35(2): 121-34. https://doi.org/10.1080/0360 1270802523577

[19] Erdemir F, Kav S, Citak EA, et al. A Turkish version of Kogan's attitude toward older people (KAOP) scale: Reliability and validity assessment. Archives of Gerontology and Geriatrics. 2011; 52(3): e162-e5.

[20] Ogiwara S, Inoue K, Koshizu S. Reliability and validity of a Japanese version of attitudes toward the Elderly Scale. Journal of Physical Therapy. 2007; 19: 27-32. https://doi.org/10.1589/jpts.19.27

[21] Lambrinou E, Sourtzi P, Kalokerinou A, et al. Attitudes and knowledge of the Greek nursing students towards older people. Nurse Education Today. 2009; 29(6): 617-22. PMid:19243864 https: //doi.org/10.1016/j.nedt.2009.01.011

[22] Lambrinou E, Surtzi P, Kalokerinou A, et al. Reliability and validity of the Greek version of Kogan's Old People Scale. Journal of Clinical Nursing. 2005; 14(10): 1241-7. PMid:16238770 https://doi.org/10.1111/j.1365-2702.2005.01229.x

[23] Soderhamn O, Lindencrona C, Gustavsson SM. Attitudes toward older people among nursing students and registered nurses in Sweden. Nurse Education Today. 2001; 21(3): 225-9. PMid:11322814 https://doi.org/10.1054/nedt.2000.0546

[24] Polit DF, Beck CT. Essentials of Nursing Research: Appraising Evidentce for Nursing Practice. 8th ed. Philadelphia: Lippincott Williams and Wilkins; 2014.

[25] Yen CH, Liao WC, Chen YR, et al. A Chinese version of Kogan's Attitude toward Older People Scale: Reliability and validity assessment. International Journal of Nursing Studies. 2009; 46(1): 38-44.
PMid:18701105 https://doi.org/10.1016/j.ijnurstu. 200 8.05 .004

[26] Brown J, Nolan M, Davies S, et al. Transforming students' views of gerontological nursing: Realising the potential of enriched environments of learning and care: A multi-method longitudinal study. International Journal of Nursing Studies. 2008; 45(8): 1214-32. PMid:17697678 https://doi.org/10.1016/j.ijnurstu. 200 7.07.002

[27] McCann TV, Clark E, Lu S. Bachelor of Nursing students career choices: A three-year longitudinal study. Nurse Education Today. 2010; 30(1): 31-6. PMid:19540632 https://doi.org/10.1016/ j.nedt.2009.05. 014

[28] Neville C. Undergraduate nurse attitudes toward older adults and perceptions of working with older adults: An analysis of measurement instruments. Nurse Education Today. 2015; 35(1): 183-8. PMid:25245662 https://doi.org/10.1016/j.nedt. 2014.09 .001

[29] Rathnayake S, Athukorala Y, Siop S. Attitudes toward and willingness to work with older people among undergraduate nursing students in a public university in Sri Lanka: A cross sectional study. Nurse Education Today. 2016; 36(Supplement C): 439-44. https://doi.org/10.1016/j.nedt.2015.10.007

[30] Stevens JA. Student nurses' career preferences for working with older people: A replicated longitudinal survey. International Journal of Nursing Studies. 2011; 48(8): 944-51. PMid:21324457 https://doi.org/10.1016/j.ijnurstu.2011.01.004

[31] Carlson E, Idvall E. Who wants to work with older people? Swedish student nurses' willingness to work in elderly care-A questionnaire study. Nurse Education Today. 2015; 35(7): 849-53. PMid:25828090 https://doi.org/10.1016/j.nedt.2015.03.002

[32] Xiao LD, Shen J, Paterson J. Cross-Cultural Comparison of Attitudes and Preferences for Care of the Elderly Among Australian and Chinese Nursing Students. Journal of Transcultural Nursing. 2013; 24(4): 408-16. PMid:24014491 https ://doi .org/10.1177/10436596 13493329

[33] Hweidi IM, Al-Obeisat SM. Jordanian nursing students' attitudes toward the elderly. Nurse Education Today. 2006; 26(1): 23-30. PMid:16115699 https://doi.org/10.1016/j.nedt.2005.06 .003

[34] Cheng M, Cheng C, Tian Y, et al. Student nurses' motivation to choose gerontological nursing as a career in China: A survey study. Nurse Education Today. 2015; 35(7): 843-8. PMid:25792382 https://doi.org/10.1016/j.nedt.2015.03.001

[35] Hanson RM. "Is elderly care affected by nurse attitudes?" A systematic review. British Journal of Nursing. 2014; 23(4): 2259. PMid:24809152 https://doi.org/10.12968/bjon.2014.2 3.4 .225

[36] Lee SH. Attitudes of nursing students toward elderly people. Journal of Korean Gerontological Nursing. 2014; 16(1): 18-26. https : //doi.org/10.17079/jkgn.2014.16.1.18

[37] Wang CC, Liao WC, Kuo PC, et al. The Chinese version of the facts on aging quiz scale: Reliability and validity assessment. International Journal of Nursing Studies. 2010; 47(6): 742-52. PMid:20022322 https://doi.org/10.1016/j.ijnurstu.2009.11.009

[38] Wu LL. A cross-sectional survey of student nurses' attitudes and knowledge about older people. Chinese Journal of Gerontology. 2011; 31(5): 848-50. 